\title{
Towards a universal definition of competitive intelligence
}

\begin{tabular}{|c|c|}
\hline \multicolumn{2}{|c|}{$\begin{array}{l}\text { Authors: } \\
\text { Rene Pellissier }{ }^{1} \\
\text { Tshilidzi E. Nenzhelele }^{2}\end{array}$} \\
\hline \multicolumn{2}{|c|}{$\begin{array}{l}\text { Affiliations: } \\
{ }^{1} \text { School of Business } \\
\text { Leadership, University of } \\
\text { South Africa, Pretoria, } \\
\text { South Africa }\end{array}$} \\
\hline \multicolumn{2}{|c|}{$\begin{array}{l}{ }^{2} \text { Department of Business } \\
\text { Management, University of } \\
\text { South Africa, Pretoria, } \\
\text { South Africa }\end{array}$} \\
\hline \multicolumn{2}{|c|}{$\begin{array}{l}\text { Correspondence to: } \\
\text { Rene Pellissier }\end{array}$} \\
\hline \multicolumn{2}{|c|}{$\begin{array}{l}\text { Email: } \\
\text { pellir@unisa.ac.za }\end{array}$} \\
\hline \multicolumn{2}{|c|}{$\begin{array}{l}\text { Postal address: } \\
\text { PO Box 392, Pretoria 0003, } \\
\text { South Africa }\end{array}$} \\
\hline \multicolumn{2}{|c|}{$\begin{array}{l}\text { Dates: } \\
\text { Received: } 18 \text { Feb. } 2013 \\
\text { Accepted: } 13 \text { Aug. } 2013 \\
\text { Published: } 15 \text { Oct. } 2013\end{array}$} \\
\hline \multicolumn{2}{|c|}{$\begin{array}{l}\text { How to cite this article: } \\
\text { Pellissier, R. \& Nenzhelele, } \\
\text { T.E., 2013, 'Towards a } \\
\text { universal definition of } \\
\text { competitive intelligence', SA } \\
\text { Journal of Information } \\
\text { Management 15(2), Art. } \\
\text { \#559, } 7 \text { pages. http://dx.doi. } \\
\text { org/10.4102/sajim.v15i2.559 }\end{array}$} \\
\hline \multicolumn{2}{|c|}{$\begin{array}{l}\text { Copyright: } \\
\text { (C) 2013. The Authors. } \\
\text { Licensee: AOSIS } \\
\text { OpenJournals. This wo } \\
\text { is licensed under the } \\
\text { Creative Commons } \\
\text { Attribution License. }\end{array}$} \\
\hline \multicolumn{2}{|l|}{ Read online: } \\
\hline 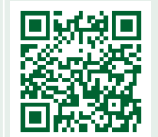 & $\begin{array}{l}\text { Scan this QR } \\
\text { code with your } \\
\text { smart phone or } \\
\text { mobile device } \\
\text { to read online. }\end{array}$ \\
\hline
\end{tabular}

Background: Enterprises face intense competition caused by globalisation. Consequently, enterprises look for tools that provide a competitive advantage. Competitive intelligence (CI) provides a competitive advantage to enterprises of all sizes. There are many definitions of CI but no universally accepted one.

Objectives: The purpose of this research is to review the current literature on CI with the aim of identifying and analysing CI definitions to establish the commonalities and differences, to propose a universal and comprehensive definition of $\mathrm{CI}$ and to set the borders of $\mathrm{CI}$ for common understanding amongst CI stakeholders.

Method: The study was qualitative in nature and content analysis was conducted on all identified sources establishing and analysing CI definitions. To identify relevant literature, academic databases and search engines were used. A review of references in related studies led to more relevant sources, the references of which were further reviewed and analysed. Keywords 'competitive intelligence', 'marketing intelligence' and 'business intelligence' were used in search engines to find relevant sources. To ensure reliability, only peer-reviewed articles were used.

Results: The majority of scholars define CI as a process and acknowledge that CI is collected from the internal and external or competitive environment. They also outline the goals of $\mathrm{CI}$, which are to help in decision-making and provide a competitive advantage.

Conclusion: The proposed definition outlines the process, purpose, source, deliverables, beneficiaries, benefit, ethicality and legality of $\mathrm{CI}$, sets out the borders of $\mathrm{CI}$ and ensures a common understanding amongst CI stakeholders.

\section{Introduction}

Enterprises face intense competition caused by globalisation (Wright, Eid \& Fleisher 2009). Consequently, enterprises look for tools that provide a competitive advantage (Weiss \& Naylor 2010). Competitive intelligence (CI) is a tool that provides a competitive advantage to enterprises and help decision-makers (Fleisher \& Wright 2009; Haataja 2011). CI evolved from economics, marketing, military theory, information science and strategic management (Muller 2006). As a profession, CI must follow a prescribed code of ethics (Roitner 2008). There are many definitions of CI in the literature. Although Brody (2008) explored the definitions of CI, he never attempted to come up with a universally accepted definition. This research aims to suggest a possible universal definition of CI.

\section{Competitive intelligence process}

Despite many researchers listing only five steps or stages of the CI process (Bose 2008), Botha and Boon (2008) identify seven steps, which are depicted in Figure 1 and briefly discussed thereafter.

Intelligence needs and determining key intelligence topics: Intelligence needs of decision-makers are ascertained and all intelligence leads are narrowed to key intelligence topics. Planning and direction: Plans and directions are formulated in order to fulfil the intelligence needs of decisionmakers. Collection: Information is collected from the external environment in an ethical and legal manner. Information processing: Collected information gets captured and stored. Analysis: Stored information is analysed to produce actionable intelligence. Dissemination: Actionable intelligence is distributed to decision-makers. Intelligence users and decision-makers: New intelligence needs are identified.

\section{Definitions of competitive intelligence}

There are many definitions of CI in the literature (Weiss \& Naylor 2010) and none has achieved worldwide acceptance (Roitner 2008). These definitions differ only by semantic changes in 




Source: Botha, D.F. \& Boon, J.A., 2008, Competitive intelligence in support of strategic training and learning, South African Journal of Information Management 10(3), 1-6. FIGURE 1: The competitive intelligence process.

language and emphasis (Brody 2008). Fleisher and Wright (2009) argue that CI practitioners rarely have time for definitions rather focus on doing their job better. Haddadi, Dousset and Berrada (2010) conclude that the lack of a universally accepted definition of CI makes it a field with unstable borders. CI is frequently confused with industrial espionage (Colakoglu 2011). Unlike CI, industrial espionage is considered unethical and illegal (Haddadi et al. 2010). According to Roitner (2008), CI is ethical and legal because it follows a code of ethics. Definitions of CI that exist in the literature are either process-oriented or product-oriented (Brody 2008). However, Roitner (2008) states that it is difficult to draw a line and to categorise $\mathrm{CI}$ as a process or a product as it comprises characteristics of both. There is therefore a need for a commonly agreed definition of CI (Roitner 2008). The literature shows that the definitions of CI have evolved over the years. The following definitions of CI were identified from the literature.

Some definitions outline the CI process, purpose and sources but overlook the deliverable, benefit, beneficiaries, ethicality and legality: $\mathrm{CI}$ is:

- A process of knowing what the competition is up to and staying one step ahead of them, by gathering information about competitors and, ideally, applying it to short- and long-term strategic planning (Dishman \& Pearson 2003).

- The process of monitoring the competitive environment to help in making informed decisions about marketing, research and development and long-term strategies (Liu \& Oppenheim 2006).

- A process of monitoring the competitive environment by pulling together data and information from a very large and strategic perspective, to predict or forecast what is going to happen in the competitive environment of an enterprise (Bose 2008).

- An ongoing, systematic evaluation of the external environment for opportunities, threats and developments that could have an impact on the enterprise and influence reactive decision-making (Strauss \& Du Toit 2010).

- The process of collecting, analysing and applying information about products, clients and competitors to meet the enterprise's long-term and short-term planning needs (Othenin-Girard, Caron \& Guillemette 2011).
Other definitions outline the $\mathrm{CI}$ process and purpose but neglect the sources, deliverable, benefit, beneficiaries, ethicality and legality: $\mathrm{CI}$ is:

- A process involving the gathering, analysing and communicating of environmental information to assist in strategic decision-making (Dishman \& Calof 2007).

- The process of collection, treatment and diffusion of information that has an objective: the reduction of uncertainty in the making of all strategic decisions (Zeng et al. 2007).

- The process of taking large amounts of data, analysing that data and presenting a high-level set of reports that condense the essence of that data into the basis of business actions, enabling management to make fundamental daily business decisions (Stackowiak, Rayman \& Greenwald 2007).

There are also definitions that acknowledge CI process, purpose, sources and deliverable but neglect the benefit, beneficiaries, ethicality and legality: $\mathrm{CI}$ is:

- A process that aims to monitor the external business environment of an organisation in order to identify relevant information for the decision-making process (Cheng, Chau \& Zeng 2002).

- The transformation of raw information about the competitive external environment into intelligence to support business decisions (Hughes 2005).

- The conversion of data and information, gathered by an organisation from its external and internal environment, into intelligence that supports the organisational decisionmaking process (Santos \& Correia 2010).

Other definitions acknowledge CI process, purpose, sources, benefit and deliverable, but neglect the benefits, beneficiaries, ethicality and legality: $\mathrm{CI}$ is:

- The process by which an enterprise collects useful information about its competitors and its competitive environment so that it can apply this information in its planning and decision-making processes to improve performance (Love 2007).

- The process by which organisations gather actionable information about competitors and the competitive environment and, ideally, apply it to their planning processes and decision-making in order to improve their enterprise's performance (Brody 2008).

Some definitions emphasise CI sources and ignore the process, purpose, deliverable, benefit, beneficiaries, ethicality and legality: $\mathrm{CI}$ is:

- The purposeful and coordinated monitoring of your competitors, wherever and whoever they may be, within a specific marketplace (Johnson 2005).

- Any type of activity aimed at monitoring competitors (potential and current) and gathering information of all types, including about human resource practices, sales and marketing, research and development and general strategy (Tarraf \& Molz 2006).

- The collection of information from competitors, customers, suppliers, technologies, environments and potential business relationships (Calof \& Wright 2008). 
Some definitions outline the CI process, purpose and deliverable, but overlook the sources, benefit, beneficiaries, ethicality and legality: $\mathrm{CI}$ is:

- An activity of collecting, processing, storing and disseminating information that is used everywhere in the organisation in order to prepare better for the future and to avoid disasters (Rouach \& Santi 2001).

- The process of transforming data and the transfer of this information to the knowledge used to support the business (decision-making) (Simoes, Coelho \& Popovic 2009).

Other definitions emphasise the CI purpose and source but overlook the process, deliverable, benefit, beneficiaries, ethicality and legality: $\mathrm{CI}$ is:

- The action of gathering, analysing and applying information about products, domain constituents, customers, and competitors for the short-term and longterm planning needs of an organisation (Fleisher 2003).

- The purposeful and coordinated monitoring of competition within a specific marketplace and helps in decision-making (Agarwal 2006).

Still other definitions acknowledge the CI process and source but neglect the purpose, deliverable, benefit, beneficiaries, ethicality and legality: $\mathrm{CI}$ is:

- The process of monitoring the competitive environment (Hamblen 2000).

- A systematic process initiated by organisations in order to gather and analyse information about competitors and the general sociopolitical and economic environment of the firm (Colakoglu 2011).

Some definitions emphasise the CI process, purpose, source and benefit, but overlook the deliverable, beneficiaries, ethicality and legality: $\mathrm{CI}$ is:

- The process by which organisations actively gather information about competitors and the competitive environment and, ideally, apply it to their decisionmaking and planning processes in order to improve their business performance (Badr, Madden \& Wright 2006).

- The process by which organisations gather information on competitors and the competitive environment, ideally using this in their decision-making and planning processes with the goal of adjusting activities to improve performance (Wright et al. 2009).

Some definitions emphasise the CI process, source and deliverable but overlook the purpose, benefit, beneficiaries, ethicality and legality: $\mathrm{CI}$ is:

- An actionable recommendation arising from a systematic process, involving planning, gathering, analysing and disseminating information on the external environment, for opportunities or developments that have the potential to affect a company or a country's competitive situation (Calof 2001).

- The information and study of the competitive environment, competitive opponents and competitive strategy, which is a procedure as well as a product (Changhuo \& Xinzhou 2003).
The following definitions emphasise the CI process, purpose, beneficiaries and deliverable but ignore the source, benefit, ethicality and legality: $\mathrm{CI}$ is:

- A value-added product resulting from the collection, evaluation, analysis, integration and interpretation of all available information that pertains to one or more aspects of a decision-makers' needs, and that is immediately or potentially significant to decision-making (Fleisher \& Benssousan 2003).

- A process that supplies employees at the management level of an organisation with relevant information in order to support tactical and strategic decision-making (Bucher, Gericke \& Sigg 2009).

Other definitions acknowledge the CI purpose, deliverable and beneficiaries but ignore the process, source, benefit, ethicality and legality: $\mathrm{CI}$ is:

- A set of coordinated actions of research, treatment and distribution of useful information to stakeholders to enable their actions and decision-making (Haddadi et al. 2010).

- A set of procedures and data sources used by marketing managers to sift information from the environment that they can use in their decision making (Nasri \& Charfeddine 2012).

Some definitions acknowledge the CI process, purpose, source, deliverable, ethics and beneficiaries but ignore the benefit and legality: $\mathrm{CI}$ is:

- A systematic, targeted, timely and ethical effort to collect, synthesise and analyse competition, markets and the external environment in order to produce actionable insights for decision-makers (Fleisher 2008).

- A systematic and planned process to ethically collect, analyse, synthesise and disseminate accurate, relevant, timely and actionable intelligence about customers, competitors, partners, markets and other environmental factors in order to asses and monitor external environment, provide early warning signals and support decision-makers in strategic and tactical decision-making (Haataja 2011).

One definition emphasises the sources and deliverable of CI but ignores the purpose, process, benefit, beneficiaries, ethicality and legality: $\mathrm{CI}$ is:

- Actionable information about the present and future behaviour of competitors, suppliers, customers, technologies, government, acquisitions, market and general business environment (Vedder \& Guynes 2000).

This definition outlines the CI deliverable and purpose but neglects process, ethicality, legality, sources, benefit and beneficiaries: $\mathrm{CI}$ is:

- Information that is analysed and provides implications for strategic planning and decision-making (Groom \& David 2001).

This definition acknowledges CI deliverable and benefit but overlooks the process, purpose, source, legality, ethicality and beneficiaries: $\mathrm{CI}$ is: 
- Any actionable intelligence that could provide a competitive edge (Prescott \& Miller 2001).

This definition emphasises the source, legality and ethicality of CI; it neglects the CI purpose, deliverable, benefit, beneficiaries and process: $\mathrm{CI}$ is:

- A legal and ethical collection of information about competitors' activities in the marketplace (Tan, Foo \& Hui 2002).

This definition is very narrow; it refers to $\mathrm{CI}$ as data and overlooks the CI process, purpose, source, ethicality, legality, beneficiaries and benefit: $\mathrm{CI}$ is:

- The focusing, analysing and 'actioning' of data (Du Toit 2003).

This definition is broad and highlights CI process, ethicality, purpose, deliverable, source and benefit but ignores CI legality and beneficiaries: $\mathrm{CI}$ is:

- The systematic process by which organisations ethically gather and analyse actionable information about competitors and the competitive environment and, ideally, apply it to their decision-making and planning processes to improve their performance (Fleisher 2004).

This definition is broader and reveals CI process, source, deliverable, ethicality and legality but it overlooks CI purpose, benefit and beneficiaries: $\mathrm{CI}$ is:

- A continuously evolving process that involves discovering, analysing and using intelligence regarding competitors and the general business environment from publicly available, non-proprietary information sources and converting it into knowledge on a continuing basis (Blenkhorn \& Fleisher 2005).

This definition outlines the CI process, benefit and source but neglects CI purpose, beneficiaries, deliverable, ethicality and legality: $\mathrm{CI}$ is:

- A process that increases marketplace competitiveness by analysing the capabilities and potential actions of individual competitors as well as the overall competitive situation of the firm in its industry and in the economy (Gray 2005).

This definition is very narrow and overlooks the CI purpose, deliverable, benefit, beneficiaries, ethicality, legality and source: $\mathrm{CI}$ is:

- The systematic collection, evaluation, and organisation of information (Hodges 2005).

This definition outlines the CI process, source, types of collected information and deliverable but it refers to $\mathrm{CI}$ as strategic knowledge and overlooks CI purpose, benefit, beneficiaries, ethicality and legality: $\mathrm{CI}$ is

- The analytical process that transforms disaggregated competitor information into relevant, accurate and useable strategic knowledge about competitor positions, performance, capabilities and intentions (Muller 2006).

This definition outlines the CI purpose, process, ethicality, legality, beneficiaries and deliverable. However, it ignores CI sources and benefit: $\mathrm{CI}$ is:
- A process that uses legal and ethical means to discover, develop and deliver the relevant intelligence needed by decision-makers in a timely manner (Pietersen 2006).

This definition outlines the CI process, deliverable, legality and source but it ignores CI purpose, benefit, beneficiaries, ethicality and legality: $\mathrm{CI}$ is:

- A process by which an organisation legally gathers, analyses and distributes the information about its competitive environment (Jin \& Bouthillier 2008).

This definition reveals the CI process, purpose and beneficiaries but overlooks CI deliverable, source, benefit, ethicality and legality: $\mathrm{CI}$ is:

- The art of collecting, processing and sorting information to be made available to people at all levels of the firm to help to shape its future and protect it against current competitive threats (Zangoueinezhad \& Moshabaki 2009).

This definition outlines the CI process and beneficiaries but it disregards CI purpose, source, benefit, deliverable, ethicality and legality: $\mathrm{CI}$ is:

- A process aimed to acquire information, filter and refine it to a suitable form and deliver it to the users within the organisation (Vuori \& Väisänen 2009).

This definition acknowledges the CI process, purpose, source and ethicality, but overlooks CI deliverable, benefit, beneficiaries and legality: $\mathrm{CI}$ is:

- An ethical process for obtaining information on the competitive environment for use in organisational decision-making (Weiss \& Naylor 2010).

This definition outlines CI deliverables, process, purpose, beneficiaries, source and type of information but ignores CI benefit, ethicality and legality: $\mathrm{CI}$ is:

- A combination of defining, gathering and analysing intelligence about products, customers, competitors and any aspect of the environment needed to support executives and managers in making strategic decisions for an organisation (Dey et al. 2011).

This definition outlines CI beneficiaries, purpose, source and types of information but pays no attention to the CI process, deliverable, benefit, ethicality and legality: $\mathrm{CI}$ is:

- An activity of the strategic management of information that aims to allow decision-makers to forestall the market trends and moves of competitors, identify and evaluate threats and opportunities that emerge in the business environment, and circumscribe actions of attack or defence that are more appropriate to the development strategy of the enterprise. (Magrinho, Franco \& Silva 2011).

This definition points out CI purpose, benefits and beneficiaries but overlooks CI process, source, deliverable, ethicality and legality: $\mathrm{CI}$ is

- A management discipline that enables executives to make smarter, more successful decisions, thereby minimising risk, avoiding being blind-sighted, and getting it right the first time (Nikolaos 2012). 


\section{Research results}

From the 50 definitions of $\mathrm{CI}$ outlined above, common and unique characteristics were identified. These characteristics are:

- Process indicates that $\mathrm{CI}$ is conducted step by step.

- Product indicates that CI is a deliverable of a completed process.

- Practice/discipline indicates that $\mathrm{CI}$ is a profession that follows a code of ethics.

- Actionable is used to indicate that CI leads to actions or decision-making.

- Systematic indicates that CI follows a planned procedure.

- Ethical indicates that CI follows an established code of ethics.

- Legal indicates that CI activities observe applicable laws in countries or regions where it is practised.

- Purpose/goal refers to the objectives of CI.

- Information refers to collection of facts or data.

- Art indicates that CI has its origin in the military.

- Activity/method refers to actions taken to complete the CI process.

- External/competitive environment indicates that information is collected from the external or competitive environment.

Figure 2 indicates CI definition characteristics and their frequency. Out of 50 definitions, 38 refer to $\mathrm{CI}$ as a process and four as a product. Thirty-five definitions declare that CI is collected from the external or competitive environment. Thirty-six definitions outline the purpose or goal of CI, which is to help in decision-making and provide a competitive advantage. Eight definitions indicate that $\mathrm{CI}$ is actionable. Only eight definitions outline that CI is ethical and five indicate that it is legally compliant. Six definitions refer to $\mathrm{CI}$ as information. Because of its military origin, three definitions refer to $\mathrm{CI}$ as an art. Seven definitions refer to $\mathrm{CI}$ as systematic. One definition refers to $\mathrm{CI}$ as an activity or method and another one refers to it as a practice or discipline. Figure 2 also highlights the percentage comparison amongst the CI characteristics.

The following comprehensive and universal definition is therefore proposed for $\mathrm{CI}$ : $\mathrm{CI}$ is:

A process or practice that produces and disseminates actionable intelligence by planning, ethically and legally collecting, processing and analysing information from and about the internal and external or competitive environment in order to help decision-makers in decision-making and to provide a competitive advantage to the enterprise.

The extensive review of the literature and analysis of the above frequencies led to the formulation of the above CI definition. The proposed definition refers to $\mathrm{CI}$ as a process because the majority of the scholars acknowledge it as such. The definition also refers to CI as an ethical and legal practice because CI, like accounting, medicine and law, is a practice conducted by professionals. The definition indicates that CI produces and disseminates actionable intelligence (intelligence that leads to action). The proposed definition reveals that $\mathrm{CI}$ is collected from the external or competitive environment

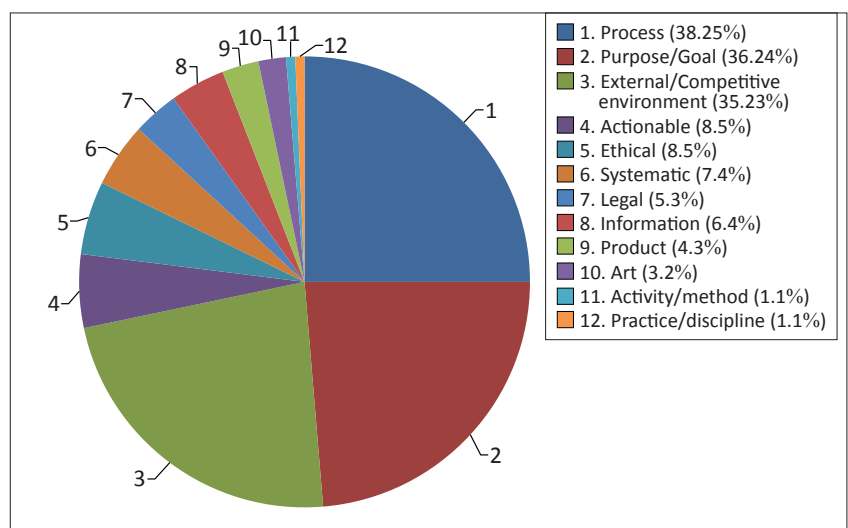

FIGURE 2: Characteristics of competitive intelligence definitions.

because the majority of the scholars outline this in their definitions. Because information for $\mathrm{CI}$ is also collected from and about the internal environment, the proposed definition outlines this. The majority of scholars reveal that the purpose or goal of CI is to help decision-makers in decision-making and the proposed definition outlines this. The proposed definition also outlines the general added benefit of $\mathrm{CI}$, which is to give enterprises competitive advantage. The proposed CI definition outlines the CI process, deliverable, ethicality, legality, source, purpose, benefit and beneficiaries. Therefore, this definition is comprehensive and clearly sets out the borders of CI for common understanding.

\section{Discussion}

The unwillingness of scholars to agree on and accept one definition of CI has led to endless definitions of CI and misunderstandings in the field. The notion that $\mathrm{CI}$ is both a process and a product has also led to several definitions: instead of finding ways to incorporate both process and product in one definition, scholars have opted to have separate definitions. The findings here reveal that the majority of these definitions refer to $\mathrm{CI}$ as a process. Most of these definitions highlight the purpose of CI, which is to help decision-makers in decision-making.

Whilst it is widely acknowledged that $\mathrm{CI}$ is ethical and legal, the majority of scholars fail to outline this in their definitions. The majority of scholars also fail to outline the $\mathrm{CI}$ deliverable in their definition. Some scholars refer to the CI deliverable as actionable information, recommendations, insight or knowledge instead of actionable intelligence. The Internet has led to information overload and referring to $\mathrm{CI}$ as information might render it useless.

Because of its military origins some scholars refer to CI as an art. Very few definitions refer to $\mathrm{CI}$ as an activity or method. Perhaps this is because most scholars value CI as a process rather than the components or steps that constitute the process. CI is a profession that follows a code of ethics, so some definitions refer to it as a practice or discipline. The majority of definitions reveal that $\mathrm{CI}$ is collected from the external or competitive environment. However, in practice, information for $\mathrm{CI}$ is also collected from within the enterprise. Although it is widely acknowledged that CI provides 
competitive advantage to enterprises, only a few scholars acknowledge this in their definitions. There is therefore no definition that is comprehensive. Most definitions focus only on certain aspects of CI, leaving out others.

\section{Conclusion}

Scholars have not agreed on one acceptable definition of CI. This has led to many definitions of CI that differ because one focuses on certain aspects of CI whilst leaving out other aspects. There is therefore no CI definition that is comprehensive. This means that the borders of the field of $\mathrm{CI}$ are not clearly outlined. Moreover, there is no common understanding amongst CI stakeholders. A universal definition of CI will ensure that CI stakeholders focus on implementing CI.

The purpose of this research was to review the current literature on $\mathrm{CI}$ with the aim of identifying and analysing CI definitions and finally to propose a universal CI definition. The proposed CI definition outlines what CI is, the deliverable of $\mathrm{CI}$, the source of $\mathrm{CI}$, how $\mathrm{CI}$ is produced, the purpose of its production, the beneficiaries of $\mathrm{CI}$ and its benefits. The proposed definition of $\mathrm{CI}$ incorporates most of the aspects that were lacking in most of the definitions of CI found. It also incorporates the aspects that were common in these CI definitions. The proposed definition of CI is therefore comprehensive and will ensure common understanding amongst CI stakeholders.

\section{Acknowledgements}

This work is based on the research supported by the National Research Foundation. The authors would also like to acknowledge the University of South Africa (South Africa) for the funding and support without which this research would not have been possible.

\section{Competing interest}

The authors declare that they have no financial or personal relationship(s) that may have inappropriately influenced them in writing this article.

\section{Authors' contributions}

T.E.N. (University of South Africa) initiated this research, conducted the literature review and analysis and wrote the conclusion. R.P. (University of South Africa) led and supervised this project, selected the journal and handled editorial matters.

\section{References}

Agarwal, K.N., 2006, 'Competitive intelligence in business decisions - An overview', Competition Forum 4(2), 309-314.

Badr, A., Madden, E. \& Wright, S., 2006, 'The contribution of $\mathrm{Cl}$ to the strategic decision making process: Empirical study of the European pharmaceutical industry', Journal of Competitive Intelligence and Management 3(4), 15-35.

Blenkhorn, D.L. \& Fleisher, C.S., 2005, Competitive Intelligence and Global Business, Greenwood Publishing Group, Westport.
Bose, R., 2008, 'Competitive intelligence process and tools for intelligence analysis', Industrial Management \& Data Systems 108(4), 510-528. http://dx.doi. org/10.1108/02635570810868362

Botha, D.F. \& Boon, J.A., 2008, 'Competitive intelligence in support of strategic training and learning', South African Journal of Information Management 10(3), 1-6.

Brody, R., 2008, 'Issues in defining competitive intelligence: An exploration', Journal of Competitive Intelligence and Management 4(3), 3-16.

Bucher, T., Gericke, A. \& Sigg, S., 2009, 'Process-centric business intelligence', Business Process Management Journal 15(3), 408-429. http://dx.doi. org/10.1108/14637150910960648

Calof, J., 2001, 'Competitive intelligence and the small firm-Requirements and barriers', in sbaer.uca.edu, viewed 13 November 2012, from http://sbaer.uca.edu/ research/icsb/2001/paper16.pdf

Calof, J.L. \& Wright, S., 2008, 'Competitive intelligence: A practitioner, academic and inter-disciplinary perspective', European Journal of Marketing 42(7/8), 717-730. http://dx.doi.org/10.1108/03090560810877114

Changhuo, B. \& Xinzhou, X., 2003, Competitor analysis, Huaxia Press, Beijing.

Cheng, H., Chau, M. \& Zeng, D., 2002, 'Cl Spider: A tool for competitive intelligence on the Web', Decision Support Systems 34(1), 1-17. http://dx.doi.org/10.1016/ S0167-9236(02)00002-7

Colakoglu, T., 2011, 'The problematic of competitive intelligence: How to evaluate and develop competitive intelligence', Procedia-Social and Behavioral Sciences 24(1) 1615-1623. http://dx.doi.org/10.1016/j.sbspro.2011.09.075

Dey, L., Haque, S.K.M., Khurdiya, A. \& Shroff, G., 2011, 'Acquiring competitive intelligence from social media', in ACM Digital Library, viewed 17 January 2011, from http://dl.acm.org/citation.cfm?id=2034621\&bnc=1

Dishman, P. \& Calof J., 2007, 'Competitive intelligence: A multiphasic precedent to marketing strategy', European Journal of Marketing 42(7/8), 766-785. http:// dx.doi.org/10.1108/03090560810877141

Dishman, P. \& Pearson, T., 2003, 'Assessing intelligence as learning within an industrial marketing group: A pilot study', Industrial Marketing Management 32(7), 615620. http://dx.doi.org/10.1016/S0019-8501(03)00030-0

Du Toit, A.S.A., 2003, 'Competitive intelligence in the knowledge economy: What is in it for South African manufacturing enterprises?', International Journal of Information Management 23(2), 111-120. http://dx.doi.org/10.1016/S02684012(02)00103-2

Fleisher, C.S., 2003, 'Should the field be called competitive intelligence or something else?', in Laurier, viewed 12 February 2013, from www.wlu.ca/documents/24243/ CICl_Chapter_5_Fleisher.doc

Fleisher, C.S., 2004, 'Competitive intelligence education: Competencies, sources, and trends', Information Management Journal, March/April, 56-62. http://dx.doi. org/10.1108/03090560810877196

Fleisher, C.S., 2008, 'Using open source data in developing competitive and marketing intelligence', European Journal of Marketing 42(7/8), 852-866. http://dx.doi. org/10.1108/03090560810877196

Fleisher, C.S. \& Benssousan, B.E., 2003, Business and competitive analysis, FT Press, Upper Saddle River.

Fleisher, C.S. \& Wright, S., 2009, 'Examining differences in competitive intelligence practice: China, Japan, and the West', Thunderbird International Business Review 51(3), 249-261. http://dx.doi.org/10.1002/tie.20263

Gray, P., 2005, Competitive Intelligence, Business Intelligence Journal 15(4), 31-37.

Groom, J.R. \& David, F.R., 2001, 'Competitive intelligence activity among small firms', SAM Advanced Management Journal, Winter, 12-20.

Haataja, J., 2011, 'Social media as a source of competitive intelligence in a pharmaceutical corporation', Master's thesis, School of Science, Aalto University.

Haddadi, A.E., Dousset, B. \& Berrada, I. 2010, 'Xplor EveryWhere - The Competitive Intelligence System for Mobile', in IEEE Xplore, viewed 13 April 2013, from http:// ieeexplore.ieee.org/stamp/stamp.jsp?tp=\&arnumber $=5945635$

Hamblen, M., 2000, 'Competitive Intelligence', Computerworld 34(5), 53.

Hodges, C., 2005, 'Competitive intelligence overview feeding the competitive analysis process', ASQ World Conference on Quality and Improvement Proceedings 59(1), 441-445.

Hughes, S., 2005, 'Competitive intelligence as competitive advantage', Journal of Competitive Intelligence and Management 3(3), 3-18.

Jin, T. \& Bouthillier, F., 2008, 'Information behavior of competitive intelligence professionals: A convergence approach', Proceedings of the 36th annual conference of the Canadian Association for Information Science (CAIS), University of British Columbia, Vancouver, June 5-7, 2008.

Johnson, A., 2005, 'What is competitor intelligence?', in Aurora WDC, viewed 17 July 2011, from http://aurorawdc.com/whatisci.htm

Liu, C. \& Oppenheim, C., 2006, 'Competitive intelligence and the development strategy of higher education in Tianjin, China', Information Development 22(1), 58-63. http://dx.doi.org/10.1177/0266666906060091

Love, A. 2007, 'Business intelligence: What is the right approach?', Chartered Accountants Journal 86(1), 18.

Magrinho, A., Franco, M. \& Silva, J.R., 2011, 'Competitive intelligence system: A research model tested in Portuguese firms', Business Process Management Journal 17(2), 332-356. http://dx.doi.org/10.1108/14637151111122374 
Muller, M.L., 2006, 'Parts of competitive intelligence: Competitor intelligence', South African Journal of Information Management 8(1), Art. \#209, 5 pages.

Nasri, W. \& Charfeddine, L., 2012, 'Motivating salespeople to contribute to marketing intelligence activities: An expectancy theory approach', International Journal of Marketing Studies 4(1), 168-175. http://dx.doi.org/10.5539/ijms.v4n1p168

Nikolaos, T., 2012, 'Competitive Intelligence: Concept, context and a case of its application', Science Journal of Business Management 2012(2), 1-15.

Othenin-Girard, C., Caron, C. \& Guillemette, M.G., 2011, 'When competitive intelligence meets geospatial intelligence', Proceedings of the 44th Hawail International Conference on System Sciences, Kauai, Hawaii, January 4-7, 2011.

Pietersen, M.A., 2006, 'Competitive intelligence at the Medical Research Council', Master's dissertation, Dept. of Information Science, University of Stellenbosch.

Prescott, J.E. \& Miller, S.H., 2001, Proven Strategies in Competitive Intelligence, John Wiley \& Sons, Inc., New York.

Roitner, A., 2008, 'Competitive intelligence in Austria: An empirical study', Master's dissertation, University of Vienna.

Rouach, D., \& Santi, P., 2001, 'Competitive intelligence adds value: Five intelligence attitudes', European Management Journal 19(1), 552-559. http://dx.doi org/10.1016/S0263-2373(01)00069-X

Santos, M. \& Correia, A., 2010, 'Competitive intelligence as a source of competitive advantage: An exploratory study of the Portuguese biotechnology industry', paper presented at the 11th European Conference on Knowledge Management Famalicão, Portugal, September 2-3, 2010.

Simoes, J.J, Coelho, P. \& Popovic, A., 2009, 'Information quality improvement as a measure of business intelligence system benefits', WSEAS Transactions on Business and Economics 9(6).
Stackowiak, R., Rayman, J. \& Greenwald, R. 2007, Oracle Data Warehousing and Business Intelligence Solutions, Wiley, Indianapolis.

Strauss, A.C. \& Du Toit, A.S.A., 2010, 'Competitive intelligence skills needed to enhance South Africa's competitiveness', Aslib Proceedings: New Information Perspective 62(3), 302-320.

Tan, B., Foo, S. \& Hui, S., 2002, 'Web information monitoring for competitive intelligence', Cybernetics and Systems: an International Journal 33(1), 225-251.

Tarraf, T. \& Molz, R., 2006, 'Competitive intelligence at small enterprises', SAM Advanced Management Journal 71(4), 24-34.

Vedder, R.G. \& Guynes, C.S., 2000, 'A study of competitive intelligence practices in organizations', The Journal of Computer Information Systems 41(2), 36-39.

Vuori, V. \& Väisänen, J., 2009, 'The use of social media in gathering and sharing competitive intelligence', 9th International Conference on Electronic Business, Macau, November 30-December 4, 2009.

Weiss, A. \& Naylor, E., 2010, 'Competitive intelligence: How independent information professionals', American Society for Information Science and Technology 37(1), 30-34. http://dx.doi.org/10.1002/bult.2010.1720370114

Wright, S., Eid, E.R. \& Fleisher, C.S., 2009, 'Competitive intelligence in practice: Empirical evidence from the UK retail banking sector', Journal of Marketing Management 25(9/10), 941-964. http://dx.doi.org/10.1362/026725709X479318

Zangoueinezhad, A. \& Moshabaki, A., 2009, 'The role of structural capital on competitive intelligence', Industrial Management \& Data Systems 109(2), 262280. http://dx.doi.org/10.1108/02635570910930136

Zeng, L., Xu, L., Shi, Z., Wang, M. and Wu, W., 2007, 'Techniques, process, and enterprise solutions of business intelligence', IEEE Conference on Systems, Man, and Cybernetics, Taipei, Taiwan, October 8-11, 2007. 